\title{
Effects of Temperature on Sporulation and Latent Period of Colletotrichum Spp. Infecting Strawberry Fruit
}

\author{
W. T. King, L. V. Madden, M. A. Ellis, and L. L. Wilson, Department of Plant Pathology, The Ohio State Univer- \\ sity, Ohio Agricultural Research and Development Center, Wooster 44691
}

\begin{abstract}
King, W. T., Madden, L. V., Ellis, M. A., and Wilson, L. L. 1997. Effects of temperature on sporulation and latent period of Colletotrichum spp. infecting strawberry fruit. Plant Dis. 81:7784.

Effects of temperature on sporulation of Colletotrichum acutatum, C. gloeosporioides, and C. fragariae, causes of anthracnose of strawberry, were determined in controlled-environment studies. Detached immature fruit were inoculated with a conidial suspension and incubated up to 36 days at constant temperatures of $5,10,15,20,25,30$, and $35^{\circ} \mathrm{C}$. Latent period (time to first sporulation) depended on temperature and ranged from 2 to 3 days at $25^{\circ} \mathrm{C}$ to 6 to 17 days at $5^{\circ} \mathrm{C}$. C. acutatum had a shorter latent period than the other species at 5 and $10^{\circ} \mathrm{C}$; at higher temperatures, latent periods of the species were very similar. During the first 4 days of sporulation, there was an optimum-type relationship between the logarithm of conidia per fruit $[\log (Y)]$ and temperature, with maximum observed sporulation (generally $10^{6}$ to $10^{7}$ conidia per fruit) from 15 to $30^{\circ} \mathrm{C}$. Sporulation increased over time at temperatures of $15^{\circ} \mathrm{C}$ and above. The greatest difference among the species was at 5 and $10^{\circ} \mathrm{C}$, where tested $C$. acutatum isolates produced from 10 to 100 more conidia per fruit than the other species. Polynomial regression equations were used successfully to represent $\log (Y)$ as a function of temperature and incubation time. The rate of increase in sporulation over time was a function of temperature, with a predicted optimum of 22 to $26^{\circ} \mathrm{C}$. Equations were validated by predicting sporulation of the three species infecting fruit attached to plants growing in controlled-environment chambers. Although the predictions tended to be slightly larger than observed, mean error [100(observed - predicted)/ observed] was only $-0.7 \%$ (95\% confidence interval: -2.4 to $1.0 \%$ ).
\end{abstract}

Anthracnose of strawberry (Fragaria $\times$ ananassa Duchesne) has become a major constraint on strawberry production in the United States $(8,15)$. All strawberry plant parts can become infected and yield losses can be substantial (18). The disease is primarily caused by Colletotrichum acutatum J. H. Simmonds, C. gloeosporioides (Penz.) Penz. \& Sacc. in Penz., and C. fragariae Brooks, although Gloeosporium spp., Glomerella cingulata (teleomorph of C. gloeosporioides), and C. dematium also have been shown to cause infection $(1,3$, 14,30,32,33). Although there has been considerable controversy about the taxonomy of the genus $(13,31)$, recent isozyme and molecular evidence confirm the uniqueness of the three primary species $(2,28)$. Within the last few years, $C$. acutatum has become the dominant species infecting strawberry fruit in many parts of the United States (9,

Corresponding author: L. V. Madden

E-mail: madden.L@osu.edu

Salaries and research support provided by state and federal funds appropriated to the Ohio Agricultural Research and Development Center, The Ohio State University.

Accepted for publication 11 October 1996.

Publication no. D-1996-1112-07R

(C) 1997 The American Phytopathological Society
12,38). Often, C. gloeosporioides and $C$. fragariae are associated with infection of parts of the plant other than fruit, but both are capable of infecting and rotting fruit $(15,36)$.

The extensive use of fungicides often is required to manage this disease $(15,18)$, and methods for reducing the number of spray applications or better timing of fungicides are needed. Disease forecasting, based on environmental conditions, may help improve spray timing and achieve a more sustainable production system (5, 19).

The epidemiology of $C$. acutatum in Ohio has been extensively studied, and research has focused on the effects of environmental conditions on infection, spore germination, splash dispersal, and disease spread $(20,21,35,37,38)$. Madden et al. (20) investigated the effect of ground cover and ambient weather conditions on the spread of anthracnose in Ohio. They determined disease incidence in strawberry plots with different ground covers (plastic, straw, or bare soil) and elucidated, by stepwise regression analysis, those weather variables most correlated with disease incidence. The best regression model describing disease incidence was based on rain amount (cm), days since introduction of inoculum, an index of infection (0 to 1 scale) based on wetness duration and temperature, and distance from spore source (20). Only half of the variation of disease incidence was explained by the equation. They suggested that inoculum production, along with other factors, would account for unexplained variability. Although results from several studies indicated the potential importance of sporulation in the epidemiology of $C$. acutatum (20), there are no reports quantifying the sporulation of this pathogen. Moreover, there is very little epidemiological research on $C$. fragariae and $C$. gloeosporioides on strawberry.

The long-term goal of this work was to help understand why $C$. acutatum has only recently become the dominant fruit-rotting pathogen and to provide information that could eventually be used for the timing of fungicide applications. The specific objectives of this study were to (i) determine the latent periods and sporulation of Colletotrichum spp. infecting strawberry fruit in relation to temperature and incubation time, (ii) compare the sporulation and latent period of selected isolates of three Colletotrichum spp., and (iii) quantify sporulation and latent period in relation to temperature and incubation time with the use of regression analysis.

\section{MATERIALS AND METHODS}

Inoculum production. Isolates of $C$. acutatum, C. fragariae, and C. gloeosporioides were obtained from infected strawberry fruit from different regions of the United States (Table 1). All cultures were maintained on potato dextrose agar (PDA) in $100 \times 15 \mathrm{~mm}$ petri dishes. Conidia from 2-week-old cultures were streaked onto new PDA plates every week with the use of a sterilized probe. To maintain pathogenicity of the isolates, conidia from previously inoculated fruit were streaked onto new PDA plates every 2 weeks. Cultures were maintained at $26^{\circ} \mathrm{C}$ with $12 \mathrm{~h}$ of light $\left(51 \mu \mathrm{E} \mathrm{s}^{-1} \mathrm{~m}^{-2}\right)$ per day.

Inoculum for fruit inoculations was prepared by scraping plates and suspending conidia in $20 \mathrm{ml}$ of deionized water. The spore suspensions were vortexed for 1.5 min, then adjusted to $2.5 \times 10^{4}$ conidia $/ \mathrm{ml}$ with the use of a hemacytometer. Based on the results of preliminary experiments, this was the lowest spore density that resulted in $100 \%$ fruit infection.

Plant maintenance. Strawberry plants (cv. Midway), obtained as transplants from Brittinghams Nursery (Salisbury, MD), were grown in $15-\mathrm{cm}$-diameter pots containing a mixture of sand, peat, and steam- 
disinfected loam (1:2:2, vol/vol/vol). New plants were planted weekly. Plants were maintained in a greenhouse at the Ohio Agricultural Research and Development Center (OARDC), Wooster, OH. Temperature in the greenhouse ranged from 16 to $26^{\circ} \mathrm{C}$. Natural sunlight was supplemented with artificial lights for $16 \mathrm{~h}$ daily. Plants were watered with deionized water each day and were fertilized biweekly with Peters 20-20-20 N-P-K fertilizer (660 $\mu \mathrm{g}$ / $\mathrm{ml}$ ).

Sporulation in detached fruit. General methods were similar to those in Madden et al. (21) and Yang et al. (37,38). Fruit, with pedicels intact, were detached from strawberry plants when at the white stage, which is when chlorophyll breakdown occurs. The fruit were rinsed in $70 \%$ ethanol for $2 \mathrm{~min}$ and then placed in plastic tubs $(24 \times 24 \times 10 \mathrm{~cm})$ containing steel mesh. The pedicel of each fruit was placed through the mesh and submerged in water to reduce fruit dessication.

Fruit were inoculated by spraying them with an atomizer until runoff $(21,37)$. Lids were placed on the tubs to maintain free moisture on the fruit surface and relative humidity $(\mathrm{RH})$ above $80 \%$. RH was measured in a separate tub without fruit by placing wet-bulb and dry-bulb thermistors immediately over the mesh. RH and temperature were recorded with a Campbell CR-21 Micrologger (Logan, UT). Tubs were placed in an incubator set at $26^{\circ} \mathrm{C}$ for $24 \mathrm{~h}$. Lids of the tubs were then removed and the tubs were placed in an incubator set at one of the following temperatures: 5 , $10,15,20,25,30$, or $35^{\circ} \mathrm{C}$. Temperature was recorded every $10 \mathrm{~min}$ to ensure consistent conditions. Duration of incubation ranged from 2 to 36 days, depending on the temperature (see Results). The sporulation of C. acutatum $\mathrm{OH}, C$. acutatum MS, $C$. fragariae $\mathrm{MS}$, and $C$. gloeosporioides $\mathrm{FL}$ (Table 1; see Table 1 for isolate designation definitions) was evaluated for all seven temperatures. Sporulation of the other isolates was evaluated only at 15,20 , 25 , and $30^{\circ} \mathrm{C}$.

The latent period was assessed as the time from inoculation until lesions ap- peared on any of the fruit. During preliminary studies, it was found that lesion appearance coincided with time of first sporulation (16).

For sporulation assessment, five fruit were randomly taken from the tubs at the temperature-dependent sampling times. Fruit weight was determined and the percent area of lesions covering the fruit was estimated visually for each fruit for $C$. acutatum $\mathrm{OH}$ and MS, C. fragariae MS, and $C$. gloeosporioides FL. Each individual fruit was placed in $50 \mathrm{ml}$ of deionized water and agitated for $1.5 \mathrm{~min}$. The fruit was removed, and the spore suspension was vortexed for $1.5 \mathrm{~min}$. Four $10-\mu \mathrm{l} \mathrm{sam}-$ ples were placed on a hemacytometer, and the density of conidia per milliliter was calculated. The mean of the samples was used to represent each fruit. Each test was done at least three times. Each species, isolate, and temperature combination was tested in random order.

Effects of free surface moisture on sporulation. A limited set of temperature/ incubation time combinations were tested with the $\mathrm{OH}$ and MS isolates of $C$. acutatum, C. fragariae MS, and C. gloeosporioides FL, to determine if free moisture on strawberry fruit affected sporulation. Procedures were the same as in the previously described experiment, except that the lids remained on the tubs during the entire incubation period. Fruit were also lightly misted daily with an atomizer, but no run-off was visible. The experiment was conducted at three temperatures: 20 , 25 , and $30^{\circ} \mathrm{C}$. Sporulation at selected incubation times was assessed as described above and compared with sporulation at the same times for infected fruit without free moisture. The differences in sporulation [in $\log$ (conidia); see data analysis, below] were divided by $\log$ (conidia) for the tests without free moisture, and then multiplied by 100 to achieve a percentage scale.

Sporulation on attached fruit. Sporulation on infected fruit attached to plants was assessed for C. acutatum $\mathrm{OH}$ and MS, C. fragariae MS, and C. gloeosporioides FL in order to validate results from de-

Table 1. Sources and designation of Colletotrichum spp. used in this study ${ }^{\mathrm{a}}$

\begin{tabular}{lll}
\hline Species/isolate & Source & State of origin \\
\hline $\begin{array}{l}\text { C. } \text { acutatum } \\
\text { ATCC \#90170 (OH) }\end{array}$ & M. Ellis, The Ohio State University & Ohio \\
Mil - 1 (MS) & B. Smith, USDA, Mississippi & Mississippi \\
CAL - A (CA) & S. Wilhelm, University of California & California \\
CT - 6 (CT) & J. LaMondia, Connecticut & \\
C. fragariae & & Mississippi \\
MS - 9 (MS) & B. Smith, USDA, Mississippi & North Carolina \\
CF - 12 (NC) & R. Milholland, North Carolina State University & \\
C. gloeosporioides & & Florida \\
CG - 162 (FL) & C. Howard, University of Florida & North Carolina \\
CG - 63 (NC) & R. Milholland, North Carolina State University &
\end{tabular}

a All isolates originally obtained from strawberry.
b Terms in parentheses are used as isolate designations.

a All isolates originally obtained from strawberry.
b Terms in parentheses are used as isolate designations.

tached fruit studies. Strawberry plants were grown in the greenhouse as described above. Plants were chosen when the fruit were at the white stage. Inoculation procedures were similar as those of Wilson et al. (35) and as previously described here, except that the pedicels of the fruit were held as fruit were sprayed with the atomizer. Immediately after inoculation, plants were placed in a controlled environmental chamber (Rheem Manufacturing Company, Asheville, NC) and misted for $24 \mathrm{~h}$ with a Hermidifier mister (Hermidifier Co., Lancaster, PA); the plants were then moved to another chamber, which was set at one of the following temperatures: $15,20,25$, or $30^{\circ} \mathrm{C}$. Lights were turned on $\left(190 \mu \mathrm{E} \mathrm{s}{ }^{-1}\right.$ $\mathrm{m}^{-2}$ ) for $14 \mathrm{~h}$ daily. $\mathrm{RH}$ averaged 40 to $60 \%$ in the chamber. Five fruit were sampled starting when lesions appeared, and sporulation was assessed as described above. Sporulation assessment was continued from 2 to 28 days, depending on the temperature. All four temperatures were not evaluated for all isolates because of limitations to plant production in the greenhouse, and the number of incubation times varied. Each test was conducted from one to three times.

Data analysis. The effects of temperature $(T)$ and incubation time from the start of sporulation $(I)$ on conidia produced per fruit $(Y)$ were quantified by regression analysis $(19,23)$. Regression models were developed assuming the following: (i) an optimal-type relationship between $Y$ and $T$, i.e., where $Y$ increased to a maximum and then decreased; and (ii) a monotonic (increasing or decreasing) relationship between $Y$ and $I$, where the minimum value for $Y$ was zero. Logarithmic polynomials models $(4,23)$ were fitted to the sporulation data.

An overall regression model for each isolate (see below) was based on separate regression analysis for each $T$. At each temperature, $\log (Y)$ was regressed on $I$ or $\log (I+1)$ to determine the most appropriate simple equation for sporulation over time. The logarithmic function of $Y$ was chosen to stabilize variances in sporulation. Moreover, to help determine the most appropriate relationship between $Y$ and $T$, $\log (Y)$ for the first 4 days at which sporulation occurred (called "initial sporulation" here) was regressed on polynomials of temperature (without a term for time) Each tested equation used two of the following terms: $T, T^{2}, T^{3}$, and $T^{4}$. Separate regression equations were calculated for each species and isolate.

An overall polynomial model for sporulation, based on the above results, was developed with the general form $\log (Y)=$ $\mathrm{f}(I, T)$ (equation 1), in which $\mathrm{f}(I, T)$ represents a linear function of some of the following terms: $I, \log (I+1), \log (I+1) T$, $\log (I+1) T^{2}, \log (I+1) T^{3}$, and $\log (I+$ 1) $T^{4}$. Randomness and normality of residuals were evaluated as described in 
Neter et al. (23) to test whether equations were appropriate for representing the data and whether statistical assumptions were not. The significance of the model coefficients (estimated parameters) was determined by $t$ tests. Coefficients of determination $\left(R^{2}\right)$ and $R^{2}$ adjusted for degrees of freedom $\left(R_{\mathrm{a}}{ }^{2}\right)$ were calculated to measure the proportion of variation explained by the models. Regression analysis was done for each repetition of the experiments separately and for the pooled data for each species and isolate.

The square root of the mean square error [the standard error about the line $(s)$ for the best-fitting regression equation] was used to calculate a standard error of the difference (SED) and least significant difference (LSD) between means.

Latent period $(L)$ was modeled with the equation $\log (L)=b_{0}+b_{1} T+b_{2} T^{2}$ (equation 2). As with the equation for sporulation, this equation was fitted to the data for each species and isolate. Evaluation of the model results was the same as for the sporulation equation.

Fruit weight $(W)$ and estimated percent area of fruit covered with lesions $(A)$ were correlated with $\log (Y)$ for the $\mathrm{OH}$ and MS
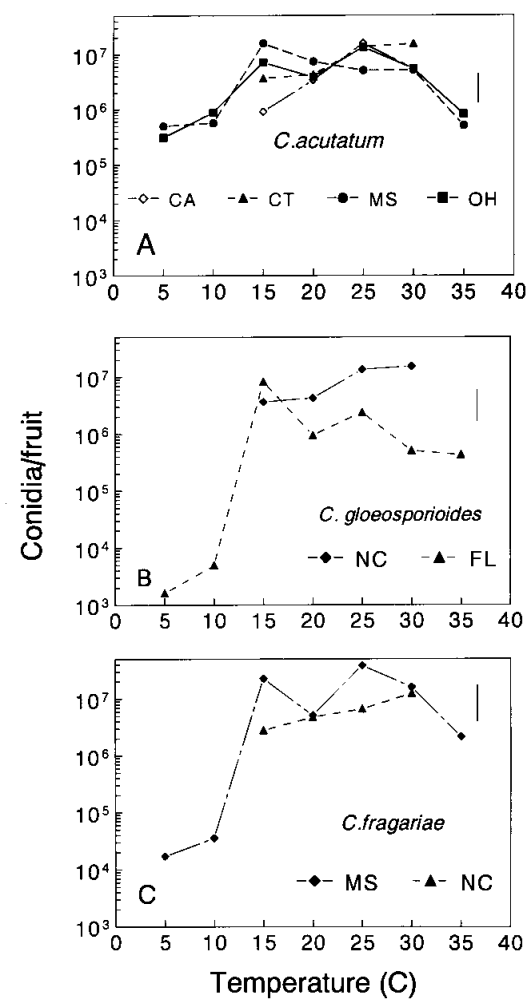

Fig. 1. Sporulation of isolates of (A) Colletotrichum acutatum, (B) C. gloeosporioides, and (C) C. fragariae in relation to temperature during incubation. Each point represents number of conidia per fruit over first 4 days at which spore production occurred. Labels (e.g., CA) indicate the state of origin. Least significant differences $(P=0.05)$ for $C$. acutatum, $C$. gloeosporioides, and $C$. fragariae $=0.31,0.33$ and 0.45 , respectively, in $\log$ units. isolates of $C$. acutatum, the $M S$ isolate of $C$. fragariae, and the $\mathrm{FL}$ isolate of $C$. gloeosporioides. Separate correlation coefficients were calculated for each isolate.

The best-fitting model for sporulation of detached fruit was used to predict sporulation on attached fruit in controlled-environmental chambers. $T$ and $I$ were based on conditions with attached fruit (in the controlled-environment chamber), but model parameters were obtained from the detached-fruit studies. A prediction interval was determined for each $T$ and $I$ combination with methods in Neter et al. (23).

\section{RESULTS}

Effects of temperature and incubation time on sporulation. An optimum-type relationship was found between temperature and sporulation. During the first 4 days after sporulation began, conidia production of all isolates was lowest at 5 and $10^{\circ} \mathrm{C}$ and increased until an optimum temperature of 15 to $25^{\circ} \mathrm{C}$ was reached (Fig. 1). Sporulation generally decreased at or above $30^{\circ} \mathrm{C}$. Colletotrichum acutatum CA, $\mathrm{CT}$, and $\mathrm{OH}$ produced about $10^{7}$ conidia per fruit at $25^{\circ} \mathrm{C}$. The two C. acutatum isolates also produced substantially more spores at low temperatures $\left(5\right.$ and $\left.10^{\circ} \mathrm{C}\right)$ than the tested isolates of the other two species. For instance, C. acutatum $\mathrm{OH}$ and MS produced $4.0 \times 10^{5}$ conidia per fruit, while $C$. gloeosporioides FL and $C$. fragariae MS produced about $10^{3}$ and $10^{4}$ conidia per fruit at $5^{\circ} \mathrm{C}$, respectively.

From 15 to $30^{\circ} \mathrm{C}$, the C. acutatum isolates generally had similar sporulation (Fig. 1A). The major difference was $C$. acutatum $\mathrm{CA}$ at $15^{\circ} \mathrm{C}$, in which there were less than $10^{6}$ conidia per fruit produced, on average. The two $C$. fragariae isolates sporulated similarly over 15 to $30^{\circ} \mathrm{C}$ (Fig. 1C). However, the $C$. gloeosporioides isolates had a large difference at $30^{\circ} \mathrm{C}$ (Fig. $1 \mathrm{~B})$, where the $\mathrm{NC}$ isolate produced more than 10 times the number of conidia per fruit as the FL isolate.

Sporulation of C. acutatum $\mathrm{OH}$ and MS, C. fragariae MS, and C. gloeosporioides FL was virtually constant over time at both 5 and $10^{\circ} \mathrm{C}$ (Figs. 2 and 3). As temperatures increased $\left(\geq 15^{\circ} \mathrm{C}\right)$, sporulation increased over time for the isolates tested. The $C$. acutatum isolates produced more spores at low temperatures over time (Fig. 2A,D) than isolates of the other two species (Fig. 3A,C). After sporulation began, maximum sporulation during the first 4 days occurred around $25^{\circ} \mathrm{C}$. At much longer incubation times (at least 14 days), maximum sporulation occurred at $15^{\circ} \mathrm{C}$ for C. acutatum CT and MS (Fig. 2B,D), $C$. gloeosporioides FL (Fig. 3A), and C. fragariae MS and NC (Fig. 3C,D). However, these long durations could not be tested at higher temperatures because of fruit degradation.

Data analysis of sporulation. The polynomial equation that best described the logarithm of sporulation per fruit $[\log (Y)]$ in relation to incubation time at each temperature was $\log (Y)=b_{0}+b_{1} \log (I+1)$ (equation 3 ), in which $b_{0}$ and $b_{1}$ are parameters (16; results not shown). Generally, a significant and positive relationship was evident between $\log (Y)$ and $\log (I+1)$ at the middle temperatures $\left(15\right.$ to $\left.30^{\circ} \mathrm{C}\right)$. Slopes $\left(b_{1}\right)$ were significantly greater than zero $(P<0.05)$, and $R^{2}$ values at middle temperatures were generally higher than values at the extreme temperatures, reflecting the higher slopes at the middle temperatures (23).

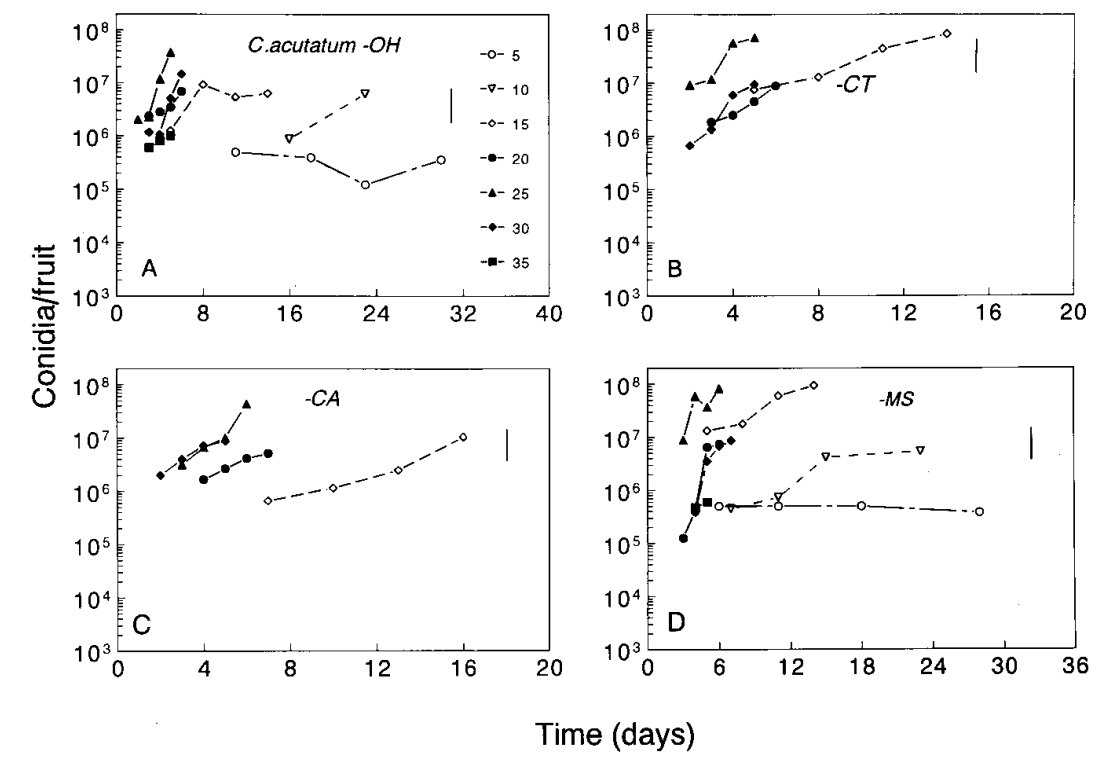

Fig. 2. Sporulation of isolates of Colletotrichum acutatum: (A) OH isolate; (B) CT isolate; (C) CA isolate; (D) MS isolate; at temperatures from 5 to $35^{\circ} \mathrm{C}$ in relation to incubation time (days). Each point represents mean number of conidia per fruit across replications. Least significant differences $(P$ $=0.05$ ) equaled 0.35 in log units. See Table 1 for definitions of isolate-designation abbreviations. 
Early sporulation (i.e., within the first 4 days after the beginning of conidia production) was best represented by $\log (Y)=$ $b_{0}+b_{1} T+b_{2} T^{3}$ (equation 4), in which $b_{0}$, $b_{1}$, and $b_{2}$ are parameters (Table 2). This equation with linear and cubic temperature terms provided the best fit to data for each species and isolate. Although $R^{2}$ values were relatively low, the statistics represent the fit of the model to individual replicate data over the 4 days and not just the means as shown in Figures 1 to $4 . R^{2}$ values ranged from 11.9 to $52.2 \%$. Based on individual $F$ tests, there were significant differences in the model results among the three species $(P<0.05)$ (Table 2$). F$ tests also indicated that there were differences among isolates within a species $(P<0.05)$, reflecting the differences in means described in the previous section. However, there were no significant $(P>0.10)$ differences in model results among repetitions.
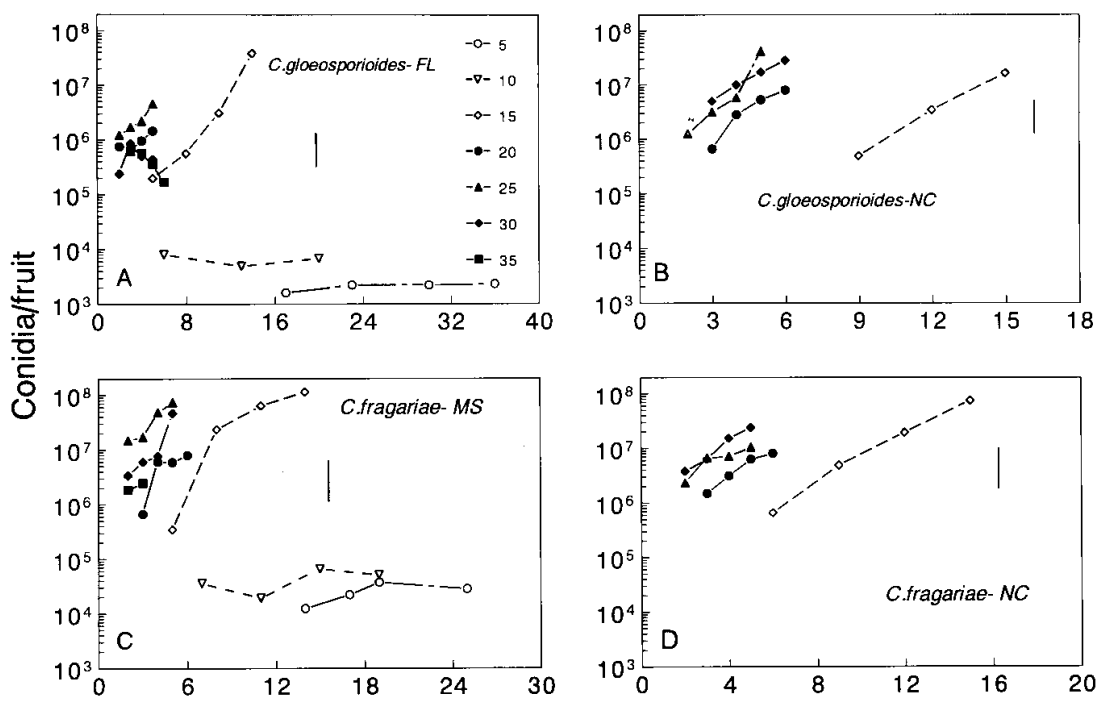

Time (days)

Fig. 3. Sporulation of isolates of Colletotrichum gloeosporioides-(A) FL isolate; (B) NC isolateand C. fragariae-(C) MS isolate; (D) $\mathrm{NC}$ isolate-at temperatures from 5 to $35^{\circ} \mathrm{C}$ in relation to incubation time (days). Each point represents mean number of conidia per fruit for replications. Least significant differences $(P=0.05)$ for $C$. gloeosporioides and $C$. fragariae $=0.46$ and 0.58 , respectively, in log units. See Table 1 for definitions of isolate-designation abbreviations.

Table 2. Estimated parameters of equation 4 for relationship between log-transformed conidia of Colletotrichum spp. on strawberry fruit $[\log (Y)]$ and temperature $(T)$ during early sporulation, together with coefficient of determination $\left(R^{2}\right), R^{2}$ adjusted for $\mathrm{df}\left(R_{\mathrm{a}}{ }^{2}\right)$, standard error about regression line $(s)$, and $\mathrm{df}^{\mathrm{a}}$

\begin{tabular}{|c|c|c|c|c|c|c|c|}
\hline \multirow[b]{2}{*}{ Species/isolate } & \multicolumn{3}{|c|}{ Regression terms } & \multirow[b]{2}{*}{$R^{2}$} & \multirow[b]{2}{*}{$R_{\mathrm{a}}^{2}$} & \multirow[b]{2}{*}{$s$} & \multirow[b]{2}{*}{ df } \\
\hline & $b_{0}$ & $T\left(b_{1}\right)$ & $T^{3}\left(b_{2}\right)$ & & & & \\
\hline \multicolumn{8}{|l|}{ C. acutatum } \\
\hline$(\mathrm{OH})^{\mathrm{b}}$ & $\begin{array}{l}4.87 \\
(0.313)^{\mathrm{c}}\end{array}$ & $\begin{array}{c}0.122 \\
(0.020)\end{array}$ & $\begin{array}{c}-0.000075 \\
(0.000012)\end{array}$ & 33.0 & 31.3 & 0.50 & 83 \\
\hline (MS) & $\begin{array}{c}5.79 \\
(0.198)\end{array}$ & $\begin{array}{c}0.158 \\
(0.092)\end{array}$ & $\begin{array}{c}-0.000008 \\
(0.00000)\end{array}$ & 25.4 & 23.3 & 0.68 & 75 \\
\hline (CA) & $\begin{array}{l}2.75 \\
(1.215)\end{array}$ & $\begin{array}{c}0.235 \\
(0.081)\end{array}$ & $\begin{array}{c}-0.000115 \\
(0.000030)\end{array}$ & 46.4 & 43.6 & 0.35 & 41 \\
\hline (CT) & $\begin{array}{l}4.72 \\
(1.013)\end{array}$ & $\begin{array}{c}0.152 \\
(0.132)\end{array}$ & $\begin{array}{c}-0.000010 \\
(0.000048)\end{array}$ & 11.9 & 7.4 & 0.56 & 41 \\
\hline \multicolumn{8}{|l|}{ C. fragariae } \\
\hline (MS) & 3.60 & 0.195 & -0.000092 & 52.4 & 51.4 & 0.69 & 86 \\
\hline (NC) & $\begin{array}{l}5.37 \\
(0.742)\end{array}$ & $\begin{array}{c}0.062 \\
(0.049)\end{array}$ & $\begin{array}{c}-0.000014 \\
(0.000041)\end{array}$ & 34.0 & 30.6 & 0.34 & 41 \\
\hline \multicolumn{8}{|c|}{ C. gloeosporioides } \\
\hline (FL) & $\begin{array}{l}4.17 \\
(0.528)\end{array}$ & $\begin{array}{c}0.1409 \\
(0.0353)\end{array}$ & $\begin{array}{c}-0.000085 \\
(0.000020)\end{array}$ & 17.8 & 15.8 & 0.92 & 86 \\
\hline (NC) & $\begin{array}{l}6.08 \\
(1.064)\end{array}$ & $\begin{array}{c}0.0152 \\
(0.0709)\end{array}$ & $\begin{array}{c}0.000017 \\
(0.000041)\end{array}$ & 20.5 & 16.4 & 0.49 & 41 \\
\hline
\end{tabular}

a See text for equation 4. Analyzed data for first 4 days after sporulation begins. First day of sporulation depends on temperature and species.

b Terms in parentheses are used as isolate designations. See Table 1 for definitions.

${ }^{\text {c }}$ Standard error of estimated parameter in parentheses.

The polynomial model that best described sporulation was of the form $\log (Y)$ $=b_{0}+b_{1} I^{\prime} T+b_{2} I^{\prime} T^{3}+b_{3} I^{\prime}$ (equation 5), in which $b_{0}$ to $b_{3}$ are parameters (Table 3 ). To improve interpretation, $I^{\prime}=\log [I+1]+$ 1 was used instead of simply $\log (I+1)$ so that the time variable $\left(I^{\prime}\right)$ was not zero on the first day of sporulation (i.e., $I^{\prime}=1$ when $I=0$ or $\log [I+1]=0)$. This addition of a constant (" 1 ") does not affect the regression goodness-of-fit results. Equation 5 was based on the combined results with equations 3 and 4 . Residuals had a random pattern and were normally distributed. The model showed a linear and cubic relationship between logarithm of sporulation and temperature, as well as a linear relationship between logarithm of sporulation and logarithm of time. There was significant difference among and within the species $(P<0.05)$ and some terms were not always significantly different from zero for some isolates. Results shown in Table 3 include only significant terms. There were no differences among repetitions $(P>$ $0.10)$.

$R^{2}$ values were $63,55,71$, and $54 \%$ for C. acutatum $\mathrm{OH}, \mathrm{MS}, \mathrm{CA}$, and $\mathrm{CT}$, respectively (Table 3 ). As with other analyses, these statistics are based on individual replicate data, and not on means. C. fragariae $\mathrm{MS}$ and $\mathrm{NC}$ and $C$. gloeosporioides had similar $R^{2}$ values. The $b_{2}$ parameter of
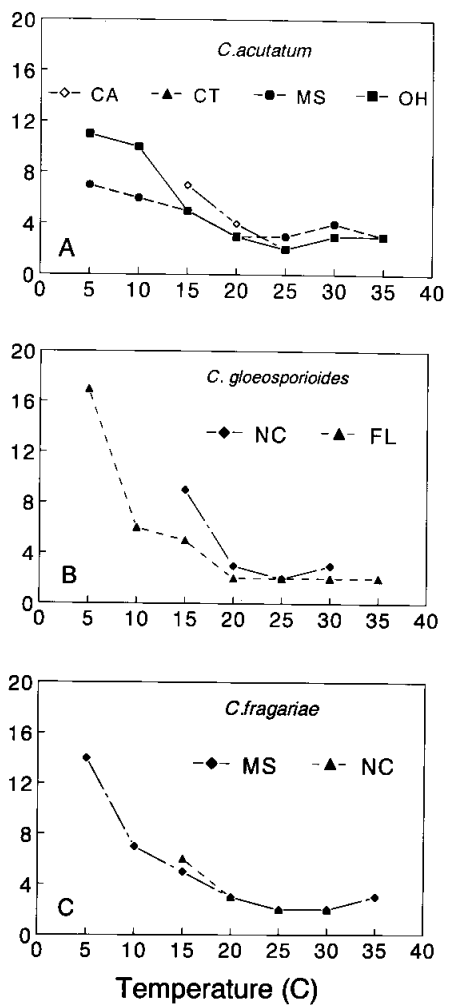

Fig. 4. Influence of temperature on latent period for isolates of (A) Colletotrichum acutatum, (B) C. gloeosporioides, and (C) C. fragariae. Each point represents mean time to first sporulation. Labels (e.g., CA) represent state of origin of isolates. 
equation 5 was generally negative, indicating the decline in sporulation at the highest temperatures. The exception was when the $b_{1}$ parameter estimate was not significantly different from zero, and omitted from the equation, $b_{2}$ was positive (C. fragariae NC; Table 3 ). The $b_{1}$ and $b_{3}$ parameters had an inverse relationship; i.e., $b_{3}$ was negative when $b_{1}$ was above 0.158 , not different from zero when $b_{1}$ was between 0.060 and 0.158 , and positive when $b_{1}$ was below 0.060 .

Equation 5 can be rewritten as $\log (Y)=$ $\mathrm{b}_{0}+I^{\prime}\left(b_{1} T+b_{2} T^{3}+b_{3}\right)$ (equation 6), to show the linear relationship between logarithm of sporulation $[\log (Y)]$ and transformed incubation time $\left(I^{\prime}\right)$, with a slope $\left(b_{1} T+b_{2} T^{3}+b_{3}\right)$ that was dependent on temperature.

Fruit weight, lesion area, and free surface moisture effects on sporulation. There were low and nonsignificant $(P>$ $0.20)$ correlation coefficients between fruit weight $(W)$ and sporulation based on an analysis of the data described above. Correlation coefficients were $-0.17,-0.08$, 0.04 , and 0.15 for $C$. acutatum $\mathrm{OH}, C$. acutatum MS, $C$. fragariae $\mathrm{MS}$, and $C$. gloeosporioides FL, respectively.

There was a positive and significant correlation $(P<0.05)$ between sporulation and estimated percent area $(A)$ of fruit covered by lesions. Correlation coefficients were $0.47,0.70,0.63$, and 0.31 for $C$. acutatum $\mathrm{OH}$, C. acutatum MS, C. fragariae MS, and $C$. gloeosporioides FL, respectively, showing the relationship between lesion size and conidia numbers. Very similar results were found for individual temperatures.

Sporulation with free surface moisture on fruit surfaces was similar but somewhat less than sporulation without surface moisture. The decline in sporulation was not greatly affected by the species or the isolates. C. acutatum MS and $\mathrm{OH}$ produced an average of 11.6 and $16.3 \%$ fewer conidia, respectively, on fruit with free surface moisture than without. C. gloeosporioides FL and $C$. fragariae MS produced 15.7 and $10.1 \%$ fewer spores, respectively.

Latent period. Latent period $(L)$ decreased as temperatures increased (Fig. 4). Latent period ranged from 6 to 17 days at $5^{\circ} \mathrm{C}$ and from 2 to 6 days at temperatures from 25 to $35^{\circ} \mathrm{C}$. The $C$. acutatum isolates had shorter latent periods than isolates of the other two species at lower temperatures. For instance, at $5^{\circ} \mathrm{C}$, latent period averaged 7 and 11 days for $C$. acutatum MS and $\mathrm{OH}$, respectively, but averaged 17 days for C. fragariae MS and 14 days for C. gloeosporioides $\mathrm{FL}$. At $25^{\circ} \mathrm{C}$, latent period for all of the isolates, except for $C$. acutatum MS, was 2 days. From 20 to $35^{\circ} \mathrm{C}$, latent period was quite similar for all isolates and species.

Latent period was best described by equation 2 with $R^{2}$ values above $90 \%$ for all isolates (Table 4). All coefficients were significantly different from zero and there were significant differences $(P<0.05)$ in the coefficients among isolates and species, mostly due to differences in $L$ at low temperatures.

Sporulation on attached fruit. There was not a wide enough range of temperatures and incubation times in the controlled-environmental chambers to develop a quantitative (i.e., regression) relationship between sporulation on attached fruit and environmental variables. However, sub-

stantial sporulation occurred at all temperatures/time combinations evaluated (Table 5). In most cases, measured sporulation was similar to that predicted by equation 5 (Table 3 ) with the parameters estimated with detached fruit. In almost all cases, the $95 \%$ prediction interval, based on the model results for detached fruit, included the observed sporulation values.

Error in prediction of sporulation was determined as $100[$ (observed - predicted)/ observed], represented in log units for each

Table 3. Estimated parameters of equation 5 for relationship between log-transformed conidia of Colletotrichum spp. on strawberry fruit $[\log (Y)]$, temperature $(T)$, and function of incubation time $\left(I^{\prime}\right)^{\mathrm{a}}$, together with coefficient of determination $\left(R^{2}\right), R^{2}$ adjusted for $\mathrm{df}\left(R_{\mathrm{a}}^{2}\right)$, standard error about regression line $(s)$, and $\mathrm{df}^{\mathrm{a}}$

\begin{tabular}{|c|c|c|c|c|c|c|c|c|}
\hline \multirow[b]{2}{*}{ Species/isolate } & \multicolumn{4}{|c|}{ Regression terms } & \multirow[b]{2}{*}{$R^{2}$} & \multirow[b]{2}{*}{$R_{\mathrm{a}}^{2}$} & \multirow[b]{2}{*}{ 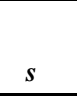 } & \multirow[b]{2}{*}{ df } \\
\hline & $b_{0}$ & $I^{\prime} T\left(b_{1}\right)$ & $I^{\prime} T^{\mathbf{3}}\left(b_{2}\right)$ & $I^{\prime}\left(b_{3}\right)$ & & & & \\
\hline \multicolumn{9}{|l|}{ C. acutatum } \\
\hline$(\mathrm{OH})^{\mathrm{b}}$ & $\begin{array}{l}4.85 \\
(0.138)^{\mathrm{d}}\end{array}$ & $\begin{array}{c}0.087 \\
(0.006)\end{array}$ & $\begin{array}{c}-0.000050 \\
(0.00004)\end{array}$ & $\ldots{ }^{c}$ & 62.6 & 61.8 & 0.37 & 99 \\
\hline (MS) & $\begin{array}{l}4.71 \\
(0.186)\end{array}$ & $\begin{array}{c}0.106 \\
(0.080)\end{array}$ & $\begin{array}{c}-0.000064 \\
(0.000007)\end{array}$ & . & 54.6 & 53.7 & 0.55 & 101 \\
\hline (CA) & $\begin{array}{l}4.91 \\
(0.204)\end{array}$ & $\begin{array}{c}0.158 \\
(0.024)\end{array}$ & $\begin{array}{c}-0.000077 \\
(0.000015)\end{array}$ & $\begin{array}{l}-1.29 \\
(0.327)\end{array}$ & 70.7 & 68.7 & 0.26 & 47 \\
\hline (CT) & $\begin{array}{c}4.82 \\
(0.342)\end{array}$ & $\begin{array}{c}0.112 \\
(0.016)\end{array}$ & $\begin{array}{c}-0.000076 \\
(0.000010)\end{array}$ & $\ldots$ & 53.7 & 51.6 & 0.44 & 47 \\
\hline \multicolumn{9}{|l|}{ C. fragariae } \\
\hline (MS) & $\begin{array}{l}4.41 \\
(0.319)\end{array}$ & $\begin{array}{c}0.161 \\
(0.012)\end{array}$ & $\begin{array}{c}-0.000075 \\
(0.000009)\end{array}$ & $\begin{array}{l}-0.82 \\
(0.220)\end{array}$ & 66.8 & 65.8 & 0.70 & 112 \\
\hline (NC) & $\begin{array}{l}4.59 \\
(0.167)\end{array}$ & $\begin{array}{l}\ldots \\
\ldots\end{array}$ & $\begin{array}{c}0.000013 \\
(0.000002)\end{array}$ & $\begin{array}{l}1.37 \\
(0.110)\end{array}$ & 80.0 & 79.1 & 0.23 & 47 \\
\hline \multicolumn{9}{|c|}{ C. gloeosporioides } \\
\hline (FL) & $\begin{array}{l}4.70 \\
(0.432)\end{array}$ & $\begin{array}{c}0.172 \\
(0.018)\end{array}$ & $\begin{array}{c}-0.000097 \\
(0.000011)\end{array}$ & $\begin{array}{l}-1.44 \\
(0.274)\end{array}$ & 48.9 & 47.3 & 0.88 & 98 \\
\hline (NC) & $\begin{array}{l}4.26 \\
(0.290)\end{array}$ & $\begin{array}{c}0.087 \\
(0.012)\end{array}$ & $\begin{array}{c}-0.000021 \\
(0.000007)\end{array}$ & $\ldots$ & 71.1 & 69.7 & 0.30 & 42 \\
\hline
\end{tabular}

${ }^{a}$ See text for equation $5 \cdot I^{\prime}=\log (I+1)+1$ in which $I$ is days, starting at the first day of sporulation (dependent on temperature and species).

b Terms in parentheses are used as isolate designations. See Table 1 for definitions.

${ }^{\mathrm{c}}$ Not significant $(P>0.10)$.

${ }^{\mathrm{d}}$ Standard error of estimated parameter in parentheses.

Table 4. Estimated parameters of equation 2 for relationship between logarithm of latent period $[\log (L)]$ of Colletotrichum spp. on strawberry fruit and temperature $(T)$, together with coefficient of determination $\left(R^{2}\right), R^{2}$ adjusted for $\mathrm{df}\left(R_{\mathrm{a}}^{2}\right)$, standard error about regression line $(s)$, and $\mathrm{df}^{\mathrm{a}}$

\begin{tabular}{|c|c|c|c|c|c|c|c|}
\hline \multirow[b]{2}{*}{ Species/isolate } & \multicolumn{3}{|c|}{ Regression terms } & \multirow[b]{2}{*}{$R^{2}$} & \multirow[b]{2}{*}{$R_{\mathrm{a}}^{2}$} & \multirow[b]{2}{*}{$s$} & \multirow[b]{2}{*}{ df } \\
\hline & $b_{0}$ & $T\left(b_{1}\right)$ & $T^{2}\left(b_{2}\right)$ & & & & \\
\hline \multicolumn{8}{|l|}{ C. acutatum } \\
\hline$(\mathrm{OH})^{\mathrm{b}}$ & $\begin{array}{l}16.43 \\
(1.759)^{\mathrm{c}}\end{array}$ & $\begin{array}{l}-1.00 \\
(0.202)\end{array}$ & $\begin{array}{c}0.0176 \\
(0.0049)\end{array}$ & 93.7 & 90.6 & 1.12 & 3 \\
\hline (MS) & $\begin{array}{c}9.57 \\
(1.006)\end{array}$ & $\begin{array}{l}-0.47 \\
(0.115)\end{array}$ & $\begin{array}{c}0.0080 \\
(0.0028)\end{array}$ & 92.0 & 88.0 & 0.65 & 6 \\
\hline (CA) & $\begin{array}{l}29.30 \\
(4.439)\end{array}$ & $\begin{array}{l}-2.08 \\
(0.404)\end{array}$ & $\begin{array}{c}0.0400 \\
(0.0089)\end{array}$ & 98.6 & 95.7 & 0.48 & 3 \\
\hline (CT) & 20.65 & -1.49 & 0.0001 & 98.9 & 96.8 & 0.22 & 3 \\
\hline \multicolumn{8}{|l|}{ C. fragariae } \\
\hline$(\mathrm{NC})$ & $\begin{array}{l}23.14 \\
(2.174)\end{array}$ & $\begin{array}{l}-1.61 \\
(0.202)\end{array}$ & $\begin{array}{c}0.0300 \\
(0.0044)\end{array}$ & 99.5 & 98.6 & 0.23 & 3 \\
\hline \multicolumn{8}{|c|}{ C. gloeosporioides } \\
\hline$(\mathrm{FL})$ & $\begin{array}{l}22.57 \\
(3.213)\end{array}$ & $\begin{array}{l}-1.65 \\
(0.368)\end{array}$ & $\begin{array}{c}0.0314 \\
(0.0089)\end{array}$ & 90.6 & 85.9 & 2.06 & 6 \\
\hline (NC) & $\begin{array}{l}46.050 \\
(6.523)\end{array}$ & $\begin{array}{l}-3.53 \\
(0.606)\end{array}$ & $\begin{array}{c}0.0700 \\
(0.0134)\end{array}$ & 98.5 & 95.6 & 0.67 & 3 \\
\hline
\end{tabular}

${ }^{a}$ See text for equation 2.

${ }^{\mathrm{b}}$ Terms in parentheses are used as isolate designations. See Table 1 for definitions.

c Standard error of the estimated parameter in parentheses. 
T/I combination with each isolate. Mean error was $-0.7 \%$, with a minimum and maximum of -17.8 and $11.8 \%$. An overall 95\% confidence interval for the error was -2.4 to $1.0 \%$, demonstrating somewhat greater overprediction than underprediction with detached fruit results.

\section{DISCUSSION}

Sporulation of Colletotrichum spp. infecting strawberry fruit was strongly influenced by temperature and incubation time. In general, there was an optimum-type relationship between conidia production and temperature, with maximum sporulation

Table 5. Sporulation of Colletotrichum spp. infecting strawberry fruit attached to plants in a controlled-environment chamber, at selected temperatures and incubation times, and predicted sporulation based on results from detached studies ${ }^{\mathrm{a}}$

\begin{tabular}{|c|c|c|c|c|c|}
\hline \multirow[b]{2}{*}{ Species/isolate } & \multirow[b]{2}{*}{$\begin{array}{c}\text { Temperature } \\
\left({ }^{\circ} \mathbf{C}\right)\end{array}$} & \multirow[b]{2}{*}{ Days } & \multicolumn{3}{|c|}{$\log ($ conidia per fruit) } \\
\hline & & & Observed & Predicted & $\begin{array}{l}95 \% \text { prediction } \\
\text { interval }^{\mathrm{b}}\end{array}$ \\
\hline C. acutatum $\mathrm{OH}^{\mathrm{c}}$ & 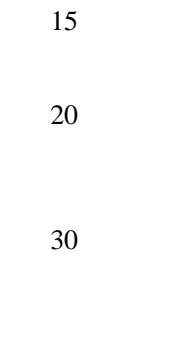 & $\begin{array}{r}10 \\
14 \\
17 \\
8 \\
10 \\
12 \\
14 \\
3 \\
4 \\
5 \\
6\end{array}$ & $\begin{array}{l}6.82 \\
7.22 \\
7.40 \\
7.00 \\
7.08 \\
7.15 \\
7.56 \\
6.30 \\
6.72 \\
6.92 \\
6.86\end{array}$ & $\begin{array}{l}7.35 \\
7.46 \\
7.53 \\
7.12 \\
7.23 \\
7.52 \\
7.62 \\
6.10 \\
6.49 \\
6.70 \\
6.86\end{array}$ & $\begin{array}{l}6.6 \text { to } 8.1 \\
6.7 \text { to } 8.2 \\
6.8 \text { to } 8.3 \\
6.4 \text { to } 7.9 \\
6.5 \text { to } 8.0 \\
6.8 \text { to } 8.3 \\
6.8 \text { to } 8.4 \\
5.4 \text { to } 6.8 \\
5.7 \text { to } 7.2 \\
5.9 \text { to } 7.4 \\
6.1 \text { to } 7.6\end{array}$ \\
\hline C. acutatum MS & 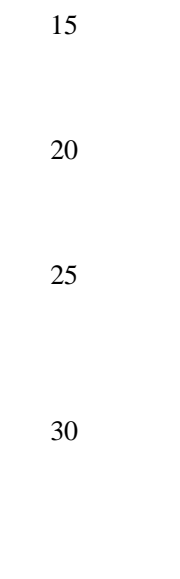 & $\begin{array}{r}7 \\
10 \\
14 \\
17 \\
6 \\
8 \\
10 \\
12 \\
2 \\
3 \\
4 \\
5 \\
6 \\
2 \\
3 \\
4 \\
5 \\
6\end{array}$ & $\begin{array}{l}6.65 \\
6.95 \\
7.30 \\
7.64 \\
6.93 \\
7.10 \\
7.65 \\
7.70 \\
6.65 \\
6.72 \\
7.15 \\
7.47 \\
7.64 \\
6.60 \\
6.90 \\
6.89 \\
7.04 \\
7.06\end{array}$ & $\begin{array}{l}6.75 \\
7.17 \\
7.47 \\
7.63 \\
7.10 \\
7.40 \\
7.69 \\
7.87 \\
6.38 \\
6.88 \\
7.17 \\
7.38 \\
7.54 \\
6.19 \\
6.63 \\
6.89 \\
7.07 \\
7.22\end{array}$ & $\begin{array}{l}5.6 \text { to } 7.8 \\
6.1 \text { to } 8.2 \\
6.3 \text { to } 8.5 \\
6.5 \text { to } 8.7 \\
6.0 \text { to } 8.2 \\
6.5 \text { to } 8.7 \\
6.6 \text { to } 8.8 \\
6.7 \text { to } 8.9 \\
5.3 \text { to } 7.4 \\
5.7 \text { to } 7.9 \\
6.0 \text { to } 8.2 \\
6.2 \text { to } 8.4 \\
6.4 \text { to } 8.6 \\
5.1 \text { to } 7.3 \\
5.5 \text { to } 7.7 \\
5.8 \text { to } 8.0 \\
6.0 \text { to } 8.2 \\
6.1 \text { to } 8.3\end{array}$ \\
\hline C. fragariae $\mathrm{MS}$ & $\begin{array}{l}25 \\
30\end{array}$ & $\begin{array}{r}15 \\
18 \\
22 \\
28 \\
2 \\
4 \\
6 \\
4 \\
6 \\
7\end{array}$ & $\begin{array}{l}6.18 \\
6.40 \\
6.70 \\
6.40 \\
6.94 \\
7.72 \\
7.90 \\
6.30 \\
6.65 \\
6.90\end{array}$ & $\begin{array}{l}6.90 \\
7.16 \\
7.34 \\
7.54 \\
6.46 \\
7.43 \\
7.88 \\
7.36 \\
7.80 \\
7.90\end{array}$ & $\begin{array}{l}5.6 \text { to } 8.4 \\
5.7 \text { to } 8.6 \\
5.9 \text { to } 8.8 \\
6.0 \text { to } 8.9 \\
5.0 \text { to } 7.8 \\
6.0 \text { to } 8.8 \\
6.5 \text { to } 9.3 \\
5.9 \text { to } 8.8 \\
6.4 \text { to } 9.2 \\
6.5 \text { to } 9.4\end{array}$ \\
\hline C. gloeosporioides FL & 25 & $\begin{array}{r}8 \\
11 \\
14 \\
17 \\
8 \\
10 \\
12 \\
14 \\
2 \\
3 \\
4 \\
5 \\
3 \\
4 \\
5 \\
6\end{array}$ & $\begin{array}{l}5.70 \\
6.00 \\
5.73 \\
6.27 \\
7.31 \\
7.48 \\
7.52 \\
7.62 \\
5.88 \\
7.01 \\
7.33 \\
7.56 \\
6.84 \\
6.74 \\
6.75 \\
6.96\end{array}$ & $\begin{array}{l}5.50 \\
6.00 \\
6.21 \\
6.41 \\
6.97 \\
7.12 \\
7.23 \\
7.32 \\
5.91 \\
6.29 \\
6.51 \\
6.67 \\
6.46 \\
6.70 \\
6.87 \\
7.01\end{array}$ & $\begin{array}{l}3.7 \text { to } 7.3 \\
4.2 \text { to } 7.7 \\
4.4 \text { to } 7.9 \\
4.6 \text { to } 8.1 \\
5.2 \text { to } 8.7 \\
5.3 \text { to } 8.9 \\
5.4 \text { to } 9.0 \\
5.5 \text { to } 9.1 \\
4.2 \text { to } 7.6 \\
4.5 \text { to } 8.0 \\
4.8 \text { to } 8.2 \\
4.9 \text { to } 8.4 \\
4.7 \text { to } 8.2 \\
4.9 \text { to } 8.4 \\
5.1 \text { to } 8.6 \\
5.2 \text { to } 8.7\end{array}$ \\
\hline
\end{tabular}

\footnotetext{
a Prediction done with equation 5 (see text) with parameter values in Table 3.
}

$\mathrm{b}$ The $95 \%$ interval is for a specific prediction of sporulation at the temperature and incubation time, not for the mean predicted sporulation at those conditions.

${ }^{c}$ Two-letter abbreviations are used as isolate designations. See Table 1 for definitions.

near $25^{\circ} \mathrm{C}$, especially within 4 days of the initiation of conidia production (Fig. 1). There was also increasing conidia production over time, especially at temperatures above $10^{\circ} \mathrm{C}$, and numbers of conidia were correlated with percentage of fruit covered by lesions. Furthermore, time to first sporulation (i.e., latent period) was greatly affected by temperature, with a decreasing latent period as temperature increased.

Sporulation of the three species was qualitatively similar but quantitatively distinct, as indicated by the different estimated regression coefficients. The greatest difference occurred between species at 5 and $10^{\circ} \mathrm{C}$, where $C$. acutatum had considerably higher sporulation than the other two species (Figs. 1-3). Moreover, $C$. acutatum had a shorter latent period at these low temperatures (Fig. 4). However, only single isolates of $C$. gloeosporioides and $C$. fragariae were tested at temperatures less than $15^{\circ} \mathrm{C}$. Around $25^{\circ} \mathrm{C}$, there was little difference in conidia production among all isolates. The greatest difference in sporulation was for $C$. gloeosporioides FL, which had a lower sporulation than the others. Likewise, latent periods were very similar at $25^{\circ} \mathrm{C}$.

A polynomial regression model (equations 5 or 6) was found to be adequate for describing sporulation (on a $\log$ scale) of the isolates of the three species in relation to temperature and incubation time (Table 3). A polynomial model (equation 2) also provided an excellent description of latent period in relation to temperature (Table 4). Although $R^{2}$ values were relatively low, these values were based on fitting the equations to individual replicate data, not the means. $R_{\mathrm{a}}{ }^{2}$ values were close to the $R^{2}$ values, indicating that terms in the model (equation 5) were all significant (23).

The change in sporulation [on a log scale; $\log (Y)]$ with incubation time was best represented by a logarithmic function of time, that is, $\log (I+1)$ in equation 3 and $I^{\prime}[\log (I+1)+1]$ in equation 5 . This is because, at some temperatures, $\log (Y)$ initially increased quickly at short incubation times and then more slowly at longer times (see Figures 2 and 3). As indicated by equation 6 , the rate of increase of $\log (Y)$ (i.e., slope) was a direct function of temperature. The maximum slope, and hence the maximum sporulation, is estimated by $T_{\text {opt }}=\left(-b_{1} / 3 b_{2}\right)^{1 / 2}$, where $b_{1}$ and $b_{2}$ are given in Table $3 . T_{\text {opt }}$ is predicted to be $24.1,23.5,26.2$, and $22.2^{\circ} \mathrm{C}$ for $C$. acutatum $\mathrm{OH}, \mathrm{MS}, \mathrm{CA}$, and $\mathrm{CT}$, respectively, $26.7^{\circ} \mathrm{C}$ for $C$. fragariae $\mathrm{MS}$, and $24.3^{\circ} \mathrm{C}$ for $C$. gloeosporioides FL. Because of the small number of temperatures tested for the other isolates, estimates of $T_{\text {opt }}$ are not meaningful based on these estimated model parameters. The optima were similar and not significantly different from each other. For some isolates (e.g., $C$. gloeosporioides FL) at long incubation times, the highest sporulation was ob- 
served at $15^{\circ} \mathrm{C}$. However, such long incubation times were tested only for relatively low temperatures due to the rapid fruit degradation and decay above $20^{\circ} \mathrm{C}$. At shorter times, greater sporulation always was observed at 25 than at $15^{\circ} \mathrm{C}$. Regression analysis results (equation 6; Table 3), showing that the slope was directly related to temperature, confirmed that optimum temperature was in the 22 to $26^{\circ} \mathrm{C}$ range.

Although the most detailed data collection and analysis done in this study used detached fruit, similar results were obtained with infected fruit still attached to plants (Table 5). With four isolates and a limited selection of temperatures and incubation times, conidia production on attached fruit was fairly well predicted by equations developed for detached fruit. Although the $95 \%$ prediction interval almost always included the observed value, the intervals were wide because of the variation in the detached fruit data. However, the average difference between observed and predicted $\log (Y)$ was only -0.037 (standard error $=0.057$ ), showing the overall closeness of the predicted sporulation to the observed. This mean difference in log units corresponds to a ratio of median observed to predicted spores (not $\log$ of spores) of 0.92 ; i.e., prediction tended to be slightly higher than observed values. Differences could be attributed to the lower RH in the chambers with plants compared with the containers with detached fruit, as well as physiological differences between detached and attached fruit.

Wilson et al. (35) previously studied the effect of temperature and wetness duration on the infection of mature and immature strawberry fruit by the Ohio isolate of $C$. acutatum. They found a similar relationship between fruit infection and temperature as found here for sporulation. There was linear increase in logit-transformed fruit disease incidence and wetness duration with a slope that was a polynomial function of temperature. Optimum temperature was between 25 and $30^{\circ} \mathrm{C}$. Relationships between epidemiological processes (i.e., infection, sporulation) and temperature and/or wetness duration for $\mathrm{Col}$ letotrichum spp. have also been studied with other hosts. For instance, Denham and Waller (6) observed an increase in disease incidence in citrus caused by $C$. gloeosporioides, with an increase in wetness duration after rain events occurring during blossoming periods. Field studies on disease incidence, along with assessments of flower development, blossom patterns, and climatic data, were used in their observations. Fitzell et al. (10) developed a polynomial model based on laboratory studies that predicted infection of mangoes by $C$. gloeosporioides var. minor based on both temperature and wetness duration. The model accounted for $87 \%$ of total variation based on laboratory results. A similar rela- tion was found by Dodd et al. (7). Optimum temperature for infection was around $25^{\circ} \mathrm{C}$. Similar results for optimum temperature were found for other crops (22, 26,27). For instance, Nair and Corbin (22) incubated pine needles (Pinus radiata) with conidia of $C$. acutatum f. sp. pinea and noted that conidia germinated within 6 $\mathrm{h}$ at an optimum of $25^{\circ} \mathrm{C}$, with appressoria formation following within $24 \mathrm{~h}$. O'Connell et al. (26) reported that conidia of $C$. truncatum, which infects pea (Pisum sativum), germinated within $4 \mathrm{~h}$ of incubation at $25^{\circ} \mathrm{C}$, and appressoria formed 10 to $15 \mathrm{~h}$ afterward. Timmer and Zitko (34) did not find a relationship between temperature and postbloom fruit drop of citrus, caused by $C$. acutatum, but their study was based on correlations of field observations. It is possible that the Florida ambient temperatures were relatively close to the optimum during the growing seasons, and thus would not be correlated with disease in the field.

Surprisingly, free surface moisture was not required for sporulation. Free moisture is required for infection of fruit by $C$. acutatum (35) and is needed for sporulation of many other fungal pathogens of fruit $(11,17)$. Related to this, Nicholson and Moraes (25) concluded that density of conidia in acervuli of $C$. graminicola, cause of anthracnose of corn, was greater under high RH than low RH due to lack of dessication of the spore matrix. Although research has been reported on spore germination and dispersal $(24,29,37,38)$, surprisingly, there have been few published reports on the influence of environmental conditions directly on spore production. Thus, it is not known if other Colletotrichum spp. are affected by moisture in a similar manner. We speculate that the pathogen obtains sufficient moisture from the ripening strawberry fruit to produce conidia.

As with sporulation, latent period was described by a polynomial function of temperature (equation 2). With this equation, the estimate of optimum temperature for $L$ is given by $-b_{1} / 2 b_{2}$. With the estimated parameters in Table 4, optimum temperature for $C$. acutatum was predicted to be 26 to $29^{\circ} \mathrm{C}$, with one exception. Due to the small numbers of temperatures tested, estimated coefficients for other species are not reliable. In general, no clear differences among isolates or species could be found in latent period around the optimum temperature. Although these estimated temperature optima for latent period are not significantly different from each other, they were similar to the optimum for infection (35). However, there was a trend for these temperature values to be somewhat larger than the estimated optima for sporulation found here.

Results from this study, along with works from previous researchers, may explain the increasing importance of $C$. $a c u$ - tatum in the north $(15,20)$. Once introduced in an area, $C$. acutatum could have distinct advantages over other strawberryinfecting species of Colletotrichum at cooler temperatures, conditions that are normal for northern regions. Two of these advantages are the short latent period for C. acutatum, and the greater production of spores at lower temperatures.

\section{LITERATURE CITED}

1. Beraha, L., and Wright, W. R. 1973. A new anthracnose of strawberry by Colletotrichum dematium. Plant Dis. Rep. 57:445-448.

2. Bonde, M. R., Peterson, G. L., and Maas, J. L. 1991. Isozyme comparisons for identification of Colletotrichum species pathogenic to strawberry. Phytopathology 81:1523-1528.

3. Brooks, A. N. 1935. Anthracnose and wilt of strawberry caused by Colletotrichum fragariae. Phytopathology 25:973-974.

4. Bulger, M. A., Ellis, M. A., and Madden, L. V. 1987. Influence of temperature and wetness duration on infection of strawberry flowers by Botrytis cinerea and disease incidence of fruit originating from infected flowers. Phytopathology 77:1225-1230.

5. Campbell, C. L., and Madden, L. V. 1990. Introduction to Plant Disease Epidemiology. Wiley-Interscience, New York.

6. Denham, T. G., and Waller, J. M. 1981. Some epidemiological aspects of postbloom fruit drop disease (Colletotrichum gloeosporioides) in citrus. Ann. Appl. Biol. 98:65-77.

7. Dodd, J. C., Estrada, A. B., Matcham, J., Jeffries, P., and Jeger, M. J. 1991. The effect of climatic factors on Colletotrichum gloeosporioides, causal agent of mango anthracnose, in the Philippines. Plant Pathol. 40:568-575.

8. Eastburn, D. M., and Gubler, W. D. 1990. Strawberry anthracnose: Detection and survival of Colletotrichum acutatum in soil. Plant Dis. 74:161-163.

9. Eastburn, D. M., and Gubler, W. D. 1992. Effects of soil moisture and temperature on the survival of Collectotrichum acutatum. Plant Dis. 76:841-842.

10. Fitzell, R. D., Peak, C. M., and Darnell, R. E. 1984. A model for estimating infection levels of anthracnose disease of mango. Ann. Appl. Biol. 104:451-458.

11. Grove, G. G., Madden, L. V., and Ellis, M. A. 1985. Influence of temperature and wetness duration on sporulation of Phytophthora cactorum on infected strawberry fruit. Phytopathology 75:700-703.

12. Gubler, W. D., and Eastburn, D. M. 1988. Research progress report: Anthracnose in California. Adv. Strawb. Prod. 7:47-50.

13. Gunnell, P. S., and Gubler, W. D. 1982. Taxonomy and morphology of Colletotrichum species pathogenic to strawberry. Mycologia 84:157-165.

14. Howard, C. M., and Albregts, E. E. 1983 Black leaf spot phase of strawberry anthracnose caused by Colletotrichum gloeosporioides $(=$ C. fragariae). Plant Dis. 67:1144-1146.

15. Howard, C. M., Mass, J. L., Chandler, C. K., and Albregts, E. E. 1992. Anthracnose of strawberry caused by the Colletotrichum complex in Florida. Plant Dis. 76:976-981.

16. King, W. T. 1995. Effects of temperature and wetness duration on immature strawberry fruit infected by Colletotrichum species. M.S. thesis. The Ohio State University, Wooster.

17. Lalancette, N., Madden, L. V., and Ellis, M. A. 1988. A quantitative model for describing the sporulation of Plasmopara viticola on grape leaves. Phytopathology 78:1316-1321.

18. Maas, J. L., ed. 1984. Compendium of Strawberry Diseases. American Phytopathological Society, St. Paul, MN. 
19. Madden, L. V., and Ellis, M. A. 1988. How to develop plant disease forecasters. Pages 191208 in: Experimental Techniques in Plant Disease Epidemiology. J. Kranz and J. Rotem, eds. Springer-Verlag, Berlin.

20. Madden, L. V., Wilson, L. L., and Ellis, M. A. 1993. Field spread of anthracnose fruit rot of strawberry in relation to ground cover and ambient weather conditions. Plant Dis. 77: 861-866.

21. Madden, L. V., Wilson, L. L., Yang, X., and Ellis, M. A. 1992. Splash dispersal of Colletotrichum acutatum and Phytophthora cactorum by short duration simulated rains. Plant Pathol. 41:427-436.

22. Nair, J., and Corbin, J. B. 1981. Histopathology of Pinus radiata seedlings infected by Colletotrichum acutatum f. sp. pinea. Trans. Br. Mycol. Soc. 81:53-63.

23. Neter, J., Wasserman, W., and Kutner, M. H. 1983. Applied Linear Regression Models. Richard D. Irwin, Homewood, IL.

24. Nicholson R. L., Hipskind, J., and Hanau, R. M. 1989. Protection against phenol toxicity by the spore mucilage of Colletotrichum graminicola, an aid to secondary spread. Physiol. Mol. Plant Pathol. 35:243-252.

25. Nicholson R. L., and Moraes, W. B. C. 1980. Survival of Colletotrichum graminicola: Im- portance of the spore matrix. Phytopathology 70:255-261.

26. O'Connell, R. J., Uronu, A. B., Waksman, G., Nash, C., and Keon, J. P. R. 1993. Hemibiotrophic infection of Pisum sativum by Colletotrichum truncatum. Plant Pathol. 42:774783.

27. Rodriguez-Marcano, A., and Sinclair, J. B. 1978. Fruiting structures of Colletotrichum dematium formed in soybean seeds. Plant Dis. Rep. 62:873-876.

28. Screenivasaprasad, S., Brown, A. E., and Mills, P. R. 1992. DNA sequence variation and interrelationships among Colletotrichum species causing strawberry anthracnose. Physiol. Mol. Plant Pathol. 41:265-281.

29. Shumway, C., Russo, V. M., and Pappelis, A. J. 1983. Germination and post-germination development of Colletotrichum dematium $\mathrm{f}$. circinans on Allium cepa. Mycopathologia 82:125-127.

30. Simmonds, J. H. 1965. A study of the species of Colletotrichum causing ripe fruit rots in Queensland. Queensl. J. Agric. Anim. Sci. 22: 437-459.

31. Smith, B. J., and Black, L. L. 1990. Morphological, cultural, and pathogenic variation among Colletotrichum species isolated from strawberry. Plant Dis. 74:69-76.
32. Sturgess, O. W. 1954. A strawberry ripe fruit rot. Queensl. J. Agric. Anim. Sci. 11:269-270.

33. Sturgess, O. W. 1957. A ripe fruit rot of the strawberry caused by a species of Gloeosporium. Queensl. J. Agric. Anim. Sci. 14:241251.

34. Timmer, L. W., and Zitko, S. E. 1993. Relationships of environmental factors and inoculum levels to the incidence of postbloom fruit drop of citrus. Plant Dis. 77:501-504

35. Wilson, L. L., Madden, L. V., and Ellis, M. A. 1990. Influence of temperature and wetness duration on infection of immature and mature strawberry fruit by Colletotrichum acutatum. Phytopathology 80:111-116.

36. Wilson, L. L., Madden, L. V., and Elllis, M A. 1994. Effect of temperature on strawberry fruit infection by geographic isolates of three Colletotrichum species. (Abstr.) Phytopathology 84:1071.

37. Yang, X., Madden, L. V., Wilson, L. L., and Ellis, M. A. 1990. Effects of surface topography and rain intensity on splash dispersal of Colletotrichum acutatum. Phytopathology 80 : 1115-1120.

38. Yang, X., Wilson, L. L., Madden, L. V., and Ellis, M. A. 1990. Rain splash dispersal of Colletotrichum acutatum from infected strawberry fruit. Phytopathology 80:590-595. 